\title{
PEMANFAATAN LINGKUNGAN LOKAL DALAM KEGIATAN LABORATORIUM BERBASIS INKUIRI TERHADAP SIKAP ILMIAH MAHASISWA CALON GURU BIOLOGI
}

\author{
Oleh
}

\author{
Reni Marlina ${ }^{1}$
}

\begin{abstract}
The aim of this research is to compare the inquirybased laboratory activities by utilizing the local environment with traditional laboratory activities on Environmental Pollution and Biological Diversity to develop a scientific attitude pre-service biology teacher. The method of this research was used quasiexperiment research with groups design alternative treatment only post-test nonequivalent. The sample were $2^{\text {nd }}$ semester pre-service biology teacher at biology education department that following the Environmental Science Course at FKIP Tanjungpura University, consist of 40 students. The instrument was used assessment scientific attitude. The results show the scientific attitude of pre-service biology teacher who use inquiry-based laboratory activities by utilizing local environment was differ significantly with the use of traditional laboratory activities.
\end{abstract}

Keywords: inquiry-based laboratory, traditional laboratory, scientific attitude, local environment

\begin{abstract}
Abstrak. Penelitian ini bertujuan untuk membandingkan kegiatan laboratorium berbasis inkuiri dengan memanfaatkan lingkungan lokal dengan kegiatan laboratorium tradisional pada perkuliahan Pengetahuan Lingkungan materi Pencemaran Lingkungan dan Keanekaragaman Hayati terhadap sikap ilmiah mahasiswa calon guru biologi. Metode yang digunakan dalam penelitian ini adalah kuasi eksperimen dengan desain penelitian "alternative treatment post-test only with nonequivalent group design". Sampel dalam penelitian ini adalah mahasiswa semester II pada program Studi Pendidikan Biologi di FKIP Universitas Tanjungpura yang berjumlah 40 mahasiswa. Instrumen yang digunakan berupa pernyataan sikap ilmiah. Hasil penelitian menunjukkan sikap ilmiah mahasiswa calon guru biologi yang menggunakan kegiatan
\end{abstract}

${ }^{1}$ Reni Marlina adalah Prodi P.Biologi, FKIP Universitas Tanjungpura Pontianak 
laboratorium berbasis inkuiri dengan memanfaatkan lingkungan lokal berbeda signifikan dengan yang menggunakan kegiatan laboratorium tradisional.

Kata Kunci: Laboratorium berbasis inkuiri, Laboratorium tradisional, sikap ilmiah, Lingkungan lokal.

\section{Pendahuluan}

Kegiatan laboratorium berbasis inkuiri dengan memanfaatkan lingkungan lokal adalah kegiatan yang diterapkan dengan menggunakan praktikum sebagai strategi bagi mahasiswa dalam menemukan sendiri fokus area penyelidikan tentang permasalahan lingkungan berdasarkan pengetahuan awal yang dimiliki mahasiswa berdasarkan lingkungan lokal. Kegiatan laboratorium berbasis inkuiri merupakan salah satu strategi pembelajaran yang memberikan kesempatan kepada mahasiswa calon guru untuk merencanakan percobaan sendiri dan dapat mengembangkan sikap ilmiah.

Lingkungan lokal merupakan kejadian, peristiwa, permasalahan, atau fenomena yang terjadi pada lingkungan daerah asal mahasiswa di Pontianak. Permasalahan lingkungan yang dijadikan sebagai media bagi mahasiswa meliputi pencemaran lingkungan dan keanekaragaman hayati. Menurut Cobern \& Aikenhead (1996), pengintegrasian lingkungan lokal dalam pembelajaran penting untuk dilakukan. Hal ini didasarkan atas alasan sebagai berikut. Pertama, pengetahuan mahasiswa tentang materi praktikum dalam bentuk lingkungan lokal yang ada di sekitar mereka merupakan pengetahuan awal yang dibawa dalam praktikum. Pengetahuan awal ini sangat bermanfaat dalam membantu mahasiswa memahami materi praktikum. Kedua, materi praktikum yang dipahami mahasiswa dengan berwawasan lingkungan lokal memberikan pengaruh terhadap peningkatan pemahaman mahasiswa terhadap lingkungannya. Ketiga, pengintegrasian lingkungan lokal dalam praktikum akan dapat meningkatkan kecintaan mahasiswa calon guru terhadap potensi (budaya) daerahnya dan keinginan untuk terus melestarikannya. Keempat, Untuk menjelaskan konsep yang dipaparkan, dapat digunakan contoh-contoh yang akrab dengan lingkungan mahasiswa calon guru biologi. Jadi, mahasiswa banyak melibatkan konteks lingkungan yang ada di sekitarnya ketika memberi contoh untuk membentuk sikap ilmiah. 
Spencer (Ahmadi, 1990) menggunakan kata sikap (attitude) untuk menunjuk suatu status mental seseorang. Ahmadi (1990) mengemukakan sikap adalah kesiapan merespon yang sifatnya positif atau negatif terhadap obyek atau situasi secara konsisten. Depdiknas (2002) belajar sains dapat membantu peserta didik untuk memahami alam dan gejalanya berkaitan dengan penelitian dan penyelidikan sehingga dapat menumbuhkan sikap ilmiah peserta.

Pada Science for All Americans: Project 2061 (Carin, 1997) dinyatakan bahwa serangkaian sikap dan nilai yang dapat ditumbuhkan melalui kerja ilmiah adalah: 1) memupuk rasa ingin tahu (being curious) dalam memahami dunia sekitarnya; 2) mengutamakan bukti dalam arti kesimpulan yang diperoleh perlu ditunjang oleh bukri empiris yang berkaitan dengan fakta; 3) bersikap skeptis; 4) mau menerima perbedaan: menghormati pandangan yang berbeda; 5) dapat bekerja sama (kooperatif); dan 6) bersikap positif terhadap kegagalan.

Kegiatan laboratorium berbasis inkuiri telah banyak diterapkan oleh peneliti dalam pembelajaran biologi antara lain: 1) hasil penelitian yang dilakukan oleh Cunningham, et al., (2006) tentang Beverage-Agarose Gel Electrophoresis: An Inquiry-based Laboratory Exercise with Virtual Adaptation yang menyatakan bahwa kegiatan laboratorium berbasis inkuiri dapat meningkatkan hasil belajar siswa SMA dan Mahasiswa S-1, 2) Hasil penelitian Kilinc (2007) tentang The Opinion Of Turkish Highschool Pupils On Inquiry Based Laboratory Activities, diketahui bahwa kegiatan laboratorium berbasis inkuiri lebih menyenangkan dibanding metode konvensional, 3) Penelitian yang dilakukan oleh Ketpichainarong, et al., (2010) tentang Enhanced learning of biotechnology students by an inquirybased cellulase laboratory yang menunjukkan bahwa kegiatan laboratorium berbasis inkuiri meningkatkan keaktifan mahasiswa dibanding metode konvensional.

Selama ini pelaksanaan perkuliahan Pengetahuan Lingkungan antara teori dan kegiatan praktikum berjalan sendiri-sendiri sehingga kadang-kadang teori tidak mendukung kegiatan praktikum. Pada kegiatan praktikum, mahasiswa calon guru biologi hanya melaksanakan percobaan dengan bantuan buku petunjuk praktikum (penuntun) yang dibuat oleh dosen pengampu mata kuliah. Penuntun yang digunakan oleh mahasiswa calon guru biologi tidak mendorong kreativitas dan keterampilan khususnya dalam sikap 
ilmiah. Hal ini disebabkan karena penuntun tersebut memuat semua langkah kerja dimulai dari tujuan hingga format tabel untuk menyajikan hasil praktikum. Akibatnya, praktikum terasa membosankan dan kreativitas mahasiswa tidak berkembang. Hal ini tentunya tidak sesuai dengan tujuan dari praktikum yang berperan memperluas pengetahuan dan wawasan mahasiswa serta meningkatkan keterampilan berpikir (minds-on) dan keterampilan bekerja (hands-on) (Halimatul, 2006). Hasil studi lapangan juga ditemukan bahwa kegiatan praktikum yang umumnya dilakukan bersifat verifikasi. Hasil penelitian Pavelic (1979) menyatakan bahwa perkembangan intelektual mahasiswa akan menjadi lebih lambat bila praktikum yang dilakukan bersifat verifikatif.

Berdasarkan uraian di atas, dirasakan perlu untuk meneliti lebih jauh tentang pemanfaatan lingkungan lokal dalam kegiatan laboratorium berbasis inkuiri terhadap sikap ilmiah mahasiswa calon guru biologi pada perkuliahan Pengetahuan Lingkungan.

\section{Metode Penelitian}

Metode penelitian yang digunakan adalah kuasi eksperimen dengan desain alternative treatment post-test only with nonequivalent group design. Sampel penelitian ini adalah mahasiswa semester II program studi Pendidikan Biologi FKIP Universitas Tanjungpura yang sedang mengambil mata kuliah Pengetahuan Lingkungan. Instrumen yang digunakan berupa pernyataan sikap ilmiah.

Data yang diperoleh berupa skor sikap ilmiah mahasiswa pada kegiatan laboratorium berbasis inkuiri berwawasan lingkungan lokal dan kegiatan laboratorium tradisional. Pengolahan data tentang perbedaan sikap ilmiah mahasiswa pada kegiatan laboratorium berbasis inkuiri dan laboratorium tradisional dihitung dengan menggunakan Software Statistical Package for Sosial Science (SPSS) for windows versi 17.0 dengan taraf signifikansi 5\%. Pengujian normalitas distribusi data dalam penelitian ini dilakukan dengan menggunakan uji Saphiro-Wilk. Uji Saphiro-Wilk merupakan uji normalitas yang sangat direkomendasikan untuk jumlah sampel kecil $(\mathrm{n}<50)$. Uji homogenitas dengan menggunakan Levene Statistic. Selain itu, untuk melihat perbedaan sikap ilmiah mahasiswa pada kegiatan laboratorium berbasis inkuiri dan laboratorium tradisional dilakukan uji hipotesis menggunakan ujit. 


\section{Hasil dan Pembahasan}

\section{Gambaran Umum Sikap ilmiah Mahasiswa}

hasil pengolahan uji statistik skor sikap ilmiah pada kegiatan laboratorium berbasis inkuiri dan pada kegiatan laboratorium tradisional dengan menggunakan bantuan aplikasi program SPSS 17. Berdasarkan hasil uji hipotesis sikap ilmiah pada kegiatan laboratorium berbasis inkuiri dan pada kegiatan laboratorium tradisional menunjukkan bahwa taraf signifikansi sikap ilmiah mahasiswa lebih rendah dibandingkan $\alpha=0.05$ sehingga $\mathrm{H}_{0}$ Ditolak. Diputuskan bahwa terdapat perbedaan yang signifikan antara sikap ilmiah pada kegiatan laboratorium berbasisi inkuiri dan pada kegiatan laboratorium tradisional. Sikap ilmiah mahasiswa calon guru biologi yang menggunakan kegiatan laboratorium berbasis inkuiri dengan memanfaatkan lingkungan lokal lebih baik dibandingkan dengan yang menggunakan kegiatan laboratorium tradisional.

Tabel 1. Rekapitulasi Uji Statistik Sikap ilmiah Mahasiswa pada Kegiatan Laboratorium Berbasis Inkuiri dan Laboratorium Tradisional.

\begin{tabular}{|c|c|c|}
\hline Komponen & \multicolumn{2}{|c|}{ Sikap ilmiah Mahasiswa } \\
\hline & Laboratorium berbasisi inkuiri & Laboratorium tradisional \\
\hline $\mathrm{N}$ & 20 & 20 \\
\hline Rata-rata & 3.9 & 3.8 \\
\hline Standar Deviasi & 0.2 & 0.3 \\
\hline Skor Maksimum & 4.3 & 4.2 \\
\hline Skor Minimum & 3.5 & 3.3 \\
\hline \multicolumn{3}{|c|}{ Uji Normalitas } \\
\hline $\begin{array}{c}\text { Nilai Signifikansi } \\
{ }_{(\text {sig. } .0=0.05)}\end{array}$ & 0.203 & 0.808 \\
\hline Keterangan & Berdistribusi Normal & Berdistribusi Normal \\
\hline \multicolumn{3}{|c|}{ Uji Homogenitas } \\
\hline $\begin{array}{c}\text { Taraf Signifikansi } \\
(\text { sig. } .=0.05)\end{array}$ & \multicolumn{2}{|c|}{0.101} \\
\hline Keterangan & \multicolumn{2}{|c|}{ Homogen } \\
\hline \multicolumn{3}{|c|}{ Uji Hipotesis } \\
\hline \multirow{2}{*}{$\begin{array}{c}\text { Taraf Signifikansi } \\
\quad(\text { sig. } .=0.05)\end{array}$} & \multicolumn{2}{|c|}{ Uji t } \\
\hline & \multicolumn{2}{|c|}{0.028} \\
\hline Keterangan & \multicolumn{2}{|c|}{$\mathrm{H}_{0}$ Ditolak } \\
\hline Kesimpulan & \multicolumn{2}{|c|}{ Terdapat Perbedaan } \\
\hline
\end{tabular}

Analisis data penelitian pada tabel 1 menunjukkan perbedaan yang signifikan antara sikap ilmiah mahasiswa pada kegiatan laboratorium 
berbasis inkuiri dan pada kegiatan laboratorium tradisional. Perbandingan rerata skor sikap ilmiah disajikan pada gambar 1.

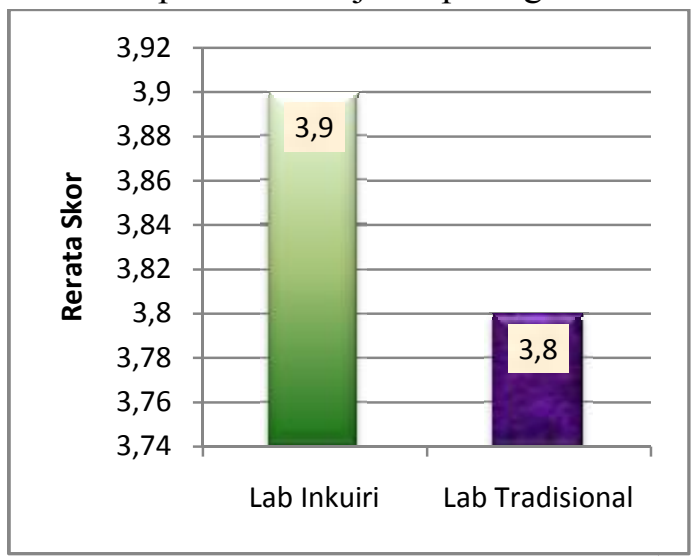

Gambar 1. Perbandingan Rerata Skor Sikap Ilmiah Pada Kegiatan Laboratorium Berbasis Inkuiri Berwawasan Lingkungan Lokal dan Pada Kegiatan Laboratorium Tradisional

Skor tertinggi adalah 5 dari setiap pernyataan sikap ilmiah. Pernyataan sikap ilmiah terdiri dari enam indikator. Perbedaan setiap indikator dalam kegiatan laboratorium berbasis inkuiri dan kegiatan laboratorium tradisional dapat dilihat pada Gambar 2.

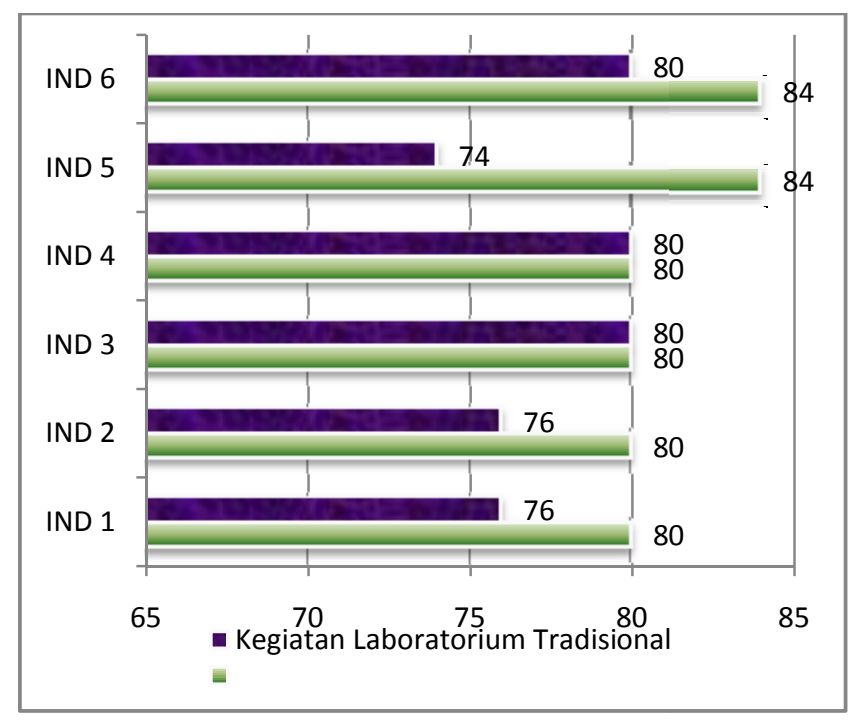


Gambar 2. Perbandingan Persentase Sikap Ilmiah Mahasiswa pada Kegiatan Laboratorium Berbasis Inkuiri Berwawasan Lingkungan Lokal dan Kegiatan Laboratorium Tradisional Pada Setiap Indikator

Keterangan:

IND-1: Rasa Ingin Tahu; IND-2: Mengutamakan Bukti; IND-3: Bersikap Skeptis; IND-4: Mau Menerima Perbedaan; IND-5: Dapat Bekerjasama; IND-6: Bersikap Positif Terhadap Kegagalan

Perbedaan sikap ilmiah ini, terjadi karena selama kegiatan laboratorium berbasis inkuiri berwawasan lingkungan lokal mahasiswa dihadapkan untuk melakukan proses ilmiah sekaligus scientific method melalui kegiatan praktikum. Hal ini sesuai dengan yang dikemukakan Nurrohman (2008), bahwa kegiatan praktikum dapat membina sikap ilmiah mahasiswa. Amin (1987) juga berpendapat bahwa untuk memperoleh ilmu pengetahuan tidak hanya dengan membaca, namun juga melalui penyelidikan fenomena kehidupan secara langsung. Penyelidikan yang dilakukan dengan cara yang sistematis melalui metode ilmiah akan menumbuhkan sikap ilmiah. Sikap ilmiah sangat penting tidak hanya untuk saat sekarang tetapi juga untuk kelangsungan hidup mereka. Oleh karena itu sangat diperlukan dalam mengevaluasi perilaku dan pemikiran siswa (Khan, 2012).

Berdasarkan wawancara non formal yang dilakukan kepada 7 mahasiswa diketahui bahwa kegiatan praktikum di lapangan yaitu di lingkungan lokal membuat mereka selalu ingin menyelidiki atau meneliti apabila menghadapi fenomena tertentu. Hal ini didukung oleh pendapat Poedjiadi (2001), sikap ingin tahu terhadap sesuatu sebenarnya merupakan sikap naluriah yang dibawa individu sejak lahir.

Selain rasa ingin tahu, mahasiswa juga memperlihatkan sikap sebagai seorang ilmuwan, yaitu tidak memanipulasi data apabila mengalami kegagalan. Menurut empat orang mahasiswa yang diwawancara secara non formal, kegagalan harus disikapi secara positif dan dikaji mengapa kegagalan itu terjadi agar tidak terulang. Hal ini didukung oleh pendapat Poedjiadi (2001), apapun hasil yang diperoleh ketika melakukan kegiatan harus tetap dikomunikasikan.

Perbedaan sikap ilmiah mahasiswa pada kegiatan laboratorium berbasis inkuiri dan laboratorium tradisional menunjukkan bahwa sikap seseorang berbeda dengan yang lainnya. Garungan (1988) berpendapat bahwa interaksi 
sosial yang terjadi di dalam atau di luar kelompok dapat mempengaruhi atau membentuk sikap yang baru. Sikap dapat berubah karena kondisi dan pengaruh yang diberikan. Sikap dapat pula dinyatakan sebagai hasil belajar sehingga sikap tidak terbentuk dengan sendirinya karena sikap senantiasa akan berlangsung dalam interaksi manusia berkenaan dengan obyek tertentu.

\section{Kesimpulan}

Hasil penelitian dan pembahasan sebelumnya menunjukkan bahwa kegiatan laboratorium berbasis inkuiri berwawasan lingkungan lokal memberikan hasil yang lebih baik dibandingkan dengan kegiatan laboratorium tradisional. Kegiatan laboratorium berbasis inkuiri berwawasan lingkungan lokal lebih memfokuskan mahasiswa sebagai subyek belajar yang telah memiliki pengetahuan awal sebelum belajar formal dan membangun pengetahuannya melalui kegiatan laboratorium, interaksi dengan dosen dan sesama teman. Secara khusus dapat disimpulkan bahwa kelompok mahasiswa yang melakukan kegiatan laboratorium berbasis inkuiri berwawasan lingkungan lokal memiliki sikap ilmiah yang lebih baik dibandingkan dengan kelompok yang melakukan kegiatan laboratorium tradisional. Kegiatan laboratorium dengan pembuatan LKM sendiri secara umum disukai oleh mahasiswa karena dapat membantu memahami materi, mengenal lebih mendalam tentang lingkungan lokal masing-masing, melatih ketelitian, dan meningkatkan motivasi. Kegiatan laboratorium berbasis inkuiri yang memperhatikan pengetahuan awal mahasiswa tidak akan mudah dilupakan.

\section{Daftar Pustaka}

Ahmadi,A. (1990). Psikologi Sosial. Jakarta: PT. Rineka Cipta.

Amin, M. (1987). Mengajarkan Ilmu Pengetahuan Alam (IPA) Dengan Menggunakan Metode "Discovery" dan "Inquiry". Jakarta: Proyek Pengembangan Lembaga Pendidikan Tenaga Kependidikan, Direktorat Jenderal Pendidikan Tinggi, Depdikbud.

Carin, A., \& Sund R.B. (1997). Teaching Science Through Discovery. Columbus, Ohio: Merill Publishing Co.

Cobern, W.W. \& Aikenhead. G.S. (1996). Culture Aspect of Learning Science. [Online]. Tersedia: http://wmich.edu/slcp/121.htm. [21 Desember 2011]. 
Cunningham.C. R., Rebecca S. P, \& Scott E. K. (2006). "Beverage-Agarose Gel Electrophoresis: An Inquiry-based Laboratory Exercise with Virtual Adaptation". Life Science education. 5, 281-286.

Departemen Pendidikan dan Kebudayaan. (2002). Pelatihan Terintegrasi Berbasis Kompetensi Guru Mata Pelajaran Biologi. Jakarta: Depdiknas.

Garungan, W.A. (1988). Psikologi Sosial. Bandung: Eresco.

Halimatul, S. (2006). Penerapan Model Hipotesis Deduktif pada Praktikum Kinetika Enzim pntuk Mengembangkan Keterampilan Berpikir Kritis Mahasiswa. Prosiding dalam seminar nasional Pendidikan IPA di UPI.

Ketpichainarong,W., Bhinyo P. \& Pintip R. (2010). "Enhanced learning of biotechnology students by an inquiry-based cellulase laboratory". International Journal of Enviromental and Science Education. 5 (2), 169-187.

Khan, S.A. (2012). The Development of Scientific Attitude in Secondary School Biology Teaching. Language In India Strength. 12 (5). 350363.

Kilinc, A. (2007). "The Opinion Of Turkish Highschool Pupils On Inquiry Based Laboratory Activities". Journal of Educational Technology. 6 (4), 56-71.

Nurohman, S. 2008. Pendekatan Project Based Learning sebagai Upaya Internalisasi Scientific Method bagi Mahasiswa Calon Guru Fisika. Tesis UNY. Yogyakarta. Tidak diterbitkan.

Pavelic, M.J. (1979). Using General Chemistry to Promote the Higher Level Thinking Abilities". Journal of Chemical Education. 59, (9), 201203.

Poedjiadi, A. (2001). Pengantar Filsafat Ilmu bagi Pendidik. Bandung: Yayasan Cendrawasih. 